Ермаков П.Н.

\title{
Феномен человека: от парадигмы мышления к парадигмам образования
}

\author{
Выступление на Первой международной \\ научно-практической конференции \\ «Психология образования: проблемы и перспективы» \\ (16-18 декабря 2004 г., Москва)
}

Особенностями сегодняшних российских реалий является то, что параллельно с теоретическим поиском, а часто и, обгоняя его, идет практическое моделирование и прямое использование уже апробированного мирового опыта в образовательной деятельности. Образование перестраивается начиная с начального, по-новому осмысливая цели и задачи, резко изменяя творческие приемы, стиль и технологии и даже личностные приоритеты и Я-концепцию преподавателя. Со времен создателя общественной школы и группового поурочного обучения Яна Коменского (мы называем это обучение традиционным) образование в той или иной степени претерпевает изменения, следуя за политическими и экономическими общественными потрясениями. Однако в 21 веке с точки зрения психологии образования на первый план выходит проблема творчества в процессе обучения и его трансформации по мере развития мышления и образовательных психотехнологий. Многочисленные исследование проблем образования, проведенные за последнее десятилетие позволяют констатировать существование различных парадигм мышления и творчества, каждой из которых соответствует определенное мироощущение, конкретные психологические проблемы, профессиональные возможности и ограничения, в конечном итоге определяющие стиль преподавательской деятельности и обучения. Сама общественная жизнь, а образование важнейший атрибут этой жизни, предстает человеку как объективировавшаяся апорея, интеллектуальнонравственная проблема, не допускающая однозначного выбора, потому что взаимоисключающие решения одинаково правильны и одинаково необходимы. Вот почему поступки современного человека нередко необъяснимо противоречивы, непонятны для него самого, как говорят психологи, «амбивалентны», то есть с равным основанием позволяют пред- 
полагать прямо противоположные мотивы и взаимоисключающие чувства.

Общественная мысль в пространстве высшей школы оказалась в плену политических антиномий, то есть сшибки концепций взаимоисключающих, опровергающих друг друга, но в то же время производящих впечатление, что по отдельности они могут быть с одинаковой убедительностью доказаны в качестве правильных. И все-таки со времен Аристотеля «не было найдено ни одного решения, с которым бы все согласились».

Кардинальный вопрос, который каждый преподаватель обязательно, на разных этапах свой преподавательской карьеры жизни задавал себе, « для чего мы ИХ учим». И каждый раз отвечал по-разному. Ответ, который мы ищем внутри себя и вокруг которого могут группироваться другие возможные ответы, состоит в очень тривиальном постулате: «Для того, чтобы человек мог себя профессионально самореализовывать».

Антиномичность мышления в этом случае проявляет себя в том, что каждая новая парадигма мышления отрицает предыдущую, но с другой стороны, она продолжает существовать параллельно. Та же картина наблюдается и в образовательных технологиях. По сути дела, сколько существует учителей начальных классов, столько же существует и технологий. Потому что каждый учитель формирует не мышление по конкретному предмету, обучая чтению, письму, рисованию и т.д., а личность ребенка и, то, что не «дадено» в этом возрасте восполнить практически невозможно. Как в беге на короткие дистанции - то, что потеряно на старте, наверстать на финише редко, кому удается. «Сумма технологий» Станислава Лема выстраивается в пирамиду - от начальной школы к высшей: чем более высокий уровень образования, тем меньше эта сумма, но тем крупнее и мощнее технологии. Иерархический принцип построения технологий находит здесь свое отражение в полной мере, от монопарадигмальных к межпарадигмальным. Каждая последующая технология включает в себя предыдущую не подменяя ее, а интегрируя и обобщая. Здесь в полной мере проявляется цикличность развития познавательных процедур: систематизация проблем и накопление приемов их анализа - разработка системы гипотез и экспериментальных методов их верификации - четкая теория, в соответствии с которой организуется исследовательская практика, - исчерпание объяснительной силы и кризис теории - переход к новому циклу. Высший период подобного цикла, когда теория четко выражена, методы исследования применяются повсеместно, а достижения несомненны, Томас Кун назвал парадиг- 
мой (от греческого - пример, образец), чтобы подчеркнуть: это своего рода общепринятый алгоритм, по которому разворачивается мыслительный процесс в обществе как коллективном субъекте познания. Предложенное Т. Куном понятие было ценным не само по себе. Оно дало возможность представить парадоксальную феноменологию современных научных революций как традиционную смену парадигм науки и обосновать несколько сугубо социальных момента познания:

- во-первых, поэтапность развития мышления (от парадигмы к парадигме);

- во-вторых, уже упоминавшаяся параллельная истинность выводов прошлых и действующих парадигм наук и образования (квантовая фризика и классическая фризика; различные системы и формы обучения и т.д.);

- в-третьих, определяющее влияние устойчивой парадигмы на все формы творчества современников, разделяющих ее установки, пока очередная «сумасшедшая идея» не откроет новую перспективу;

- в-четвертых, способность человека сознательно переходить в ту или иную парадигму в зависимости от предмета исследований и обстоятельств жизни.

Разумеется, парадигма это еще не все в науке. Также как и наука еще не все в мышлении, а мышление еще не все в психике, но взаимодействие этих категорий далеко от однозначности количественных отношений. Конечно, в потенции психика человека имеет достаточный ресурс для обеспечения любого типа миросозерцания и любой парадигмы мышления. Вопрос в том, какие именно ментальные программы инсталлированны в ней на прошлых этапах развития общества и какие именно парадигмы мышления, стили творчества, обучения и паттерны поведения задействованы ею в данной конкретной психоисторической ситуации. Косность и большая инерционность образования сыграли положительную роль в политической ситуации в России в последние 15-20 лет. Во многом благодаря устойчивой системе образования удалось достигнуть относительной политической и психологической стабильности. И именно на этом последнем фоне - рефрормы образования. Сегодня можно констатировать, что прежняя система с мифической модернизацией, еще не уступила место новой. Но обратной дороги нет. Осознание национальных приоритетов в системе общеевропейских и мировых ценностей неминуемо приведет к кардинальному изменению системы образования. Чтобы выстоять в условиях перепадов которые переживает страна, обществу как никогда нужны активность, предприимчивость, инициа- 
тива каждого человека. А где их взять, эти активность, предприимчивость, инициативность? На каком генетическом материале можно выстраивать и апробировать психосоциальные и образовательные технологии?

Образовательная технология, на мой взгляд, - это, прежде всего, продуманная во всех деталях, визуализированная и осмысленная модель совместной педагогической деятельности по проектированию, организации и проведению учебного процесса с безусловным обеспечением комфортных условий для обучаемого и обучающего. Только когда образовательная технология наполняется смыслом, она становится содержательным обобщением и инструментом образования. Не может быть качества ради качества, даже ради его псевдонаучного определения. И использования тестов или кредитной системы - это еще не изменение (или улучшение) качества. Вообще говоря «реализация идей» не является реализацией идеи. Динамика «реализации идей» все больше подминает под себя сами идеи. Провозглашается польза, прагматичность и забывается кантовское «бескорыстие». Технологии получают статус науки благодаря тому, что преподаватели и учителя, как всегда, таскают каштаны из огня не для себя. Гегелевская диалектика все равно возьмет свое - количество только тогда перейдет в качество, когда новая парадигма утвердится в умах подавляющего большинства тех, кто учит других. Антиномичность образовательных технологий и есть условие обеспечения качества образования. Я перечислю лишь некоторые из технологий, что-то уже звучало в сегодняшних выступлениях, что-то может быть дополнено:

- современное традиционное обучение (в сущности, мало, чем отличается от системы обучения Я. Коменского);

- педагогические технологии на основе личностной ориентации педагогического процесса (здесь и педагогика сотрудничества, и гуманно-личностная технология Амонашвили, и система Ильина);

- педагогические технологии на основе активации и интенсификации деятельности учащихся (игровые технологии, проблемное обучение, технологии коммуникативного обучения Пассова. Технологии интенсификации обучения на основе схемных и знаковых моделей учебного материала Шаталова);

- педагогические технологии на основе эффективности управления и организации учебного процесса (технологии уровневой дифференциации, технологии индивидуализации обучения (Ин- 
ге Унт и Шадриков), технология программированного обучения) и т.д.;

- альтернативные технологии (Вальдорфская педагогика Штейнера, технология свободного труда Френе, технология мастерских);

- природосообразные технологии;

- технологии развивающего обучения Занкова, ЭльконинаДавыдова;

- смысловая педагогика (смысловая дидактика Абакумовой);

- педагогические технологии авторских школ (школа адаптирующей педагогики Ямбурга и Броде, школа завтрашнего дня Ховарда, школа - парк Тубельского) и т.д.

Различные в своей схожести по предмету, применение всех этих технологий зависит лишь от личности применяющих, от наличия или отсутствия объединяющей парадигмы мышления. И не надо тешить себя мыслью о собственной исключительности. Одним интеллектуальным приемом мы не сможем сформировать профессиональную компетентность. Расхожий миф в советское время о нашей непревзойденности генерировать идеи и теории: «Дайте нам западные технологии и мы им всем покажем». У нас нет технологий, но есть мысль и мы ее думаем. По-видимому мы все еще продолжаем думать эту самую мысль.

Другой пример, опять таки культивируемый миф о превосходстве подготовки советских и постсоветских инженеров. На каком оборудовании, приборах, компьютерах, реактивах? Да в очень немногих элитных вузах это все присутствует, но не для всех. А может быть и не надо для всех? Может быть лучше сосредоточить ресурсы и человеческие и материальные в немногих учебных заведениях, ужесточив отбор и готовить молодых талантливых людей к поискам лучшей доли где угодно, только не в родной стране? Так, как это есть сейчас. Превращая высшую школу из системы образования в систему предоставления образовательных услуг не закладываем ли мы тротиловый заряд под будущее нашего государства, под наше с вами будущее. А в чем отличие классического образования от так называемого университетского образования ведомственных и переименованных институтов, только лишь в том, что в классическом университете есть какие-то факультеты или кафедры, которых нет в вышеупомянутых вузах. Или в том, что гуманизация и гуманитаризации высшего образования кардинально изменила выпускника технического вуза. Наверное, нет. Образовательный стандарт - он везде образовательный стандарт. Преподаватели классического университета обеспечивают учебный процесс и в негосударственных вузах, и в ве- 
домственных, и в технических учебных заведениях. Дело не в наличии или отсутствии фракультета и специальности. Дело в том, что надо, по крайней мере, 90 лет быть университетом, а лучше 200, 300 лет, чтобы заслужить право называться классическим.

Мерцающий комплекс суперполноценности/гипернеполноценности - это непрекращающаяся пытка для мыслящего профессионала и постоянная угроза искажения самого педагогического процесса обучения. Лекарство от этих двух бед одно: саморефлексия образования во всех структурах обучения и на всех этапах творчества в процессе преподавания.

И вслед за апостолом Павлом мы вопрошаем: «Что польза человеку, если он приобретет весь мир, а душе своей навредит?»

Берегите свою душу и себя. 